\title{
Acceptance and Commitment Therapy and Drug Use: A Systematic Review
}

\author{
Mariana Fonseca Carvalho Maia ${ }^{1}$ \\ Bruna Ferreira dos Santos ${ }^{2}$ \\ Lorrainy Costa de Castro ${ }^{2}$ \\ Natália São Tiago Vieira ${ }^{1}$ \\ Pollyanna Santos da Silveira ${ }^{1,3}$ (D)
}

\begin{abstract}
The harmful use of psychoactive substances has been considered one of the biggest public health issues. Several approaches are used for the treatment of disorders related to substance use in the face of the challenges imposed. This study aimed to identify the empirical works that used ACT for the treatment of substance use and their respective results regarding acceptance, feasibility, and reduction in the severity of dependence, as well as the results related to comorbidities and other aspects associated with drugs use by a systematic review of the literature on the subject, using the recommendations of the Preferred Report Items for Systematic Reviews and Meta-Analyses (PRISMA) guide and searches in PubMed, APA PsycNET, SciELO, ScienceDirect, Web of Science, VHL, and LILACS. In total, 17 studies were analyzed, allowing the observation of an increase in psychological flexibility, attenuation of treatment dropout rates, and a reduction in substance use in the analyzed interventions.
\end{abstract}

Keywords: drugs, cognitive therapy, psychological intervention

\section{Terapia de Aceitação e Compromisso e Uso de Drogas: Uma Revisão Sistemática}

Resumo: O uso prejudicial de substâncias psicoativas tem sido considerado um dos maiores problemas de saúde pública. Diversas abordagens são utilizadas para o tratamento dos transtornos relacionados ao uso de substâncias diante dos desafios impostos. O presente estudo teve por objetivo identificar os trabalhos empíricos que utilizaram a ACT para o tratamento do uso de substâncias e seus respectivos resultados no que diz respeito à aceitação, viabilidade e redução da gravidade da dependência, bem como nos resultados relacionados às comorbidades e demais aspectos associados ao uso através de uma revisão sistemática da literatura acerca do tema, utilizando-se das recomendações do guia Preferred Report Items for Systematic Reviews and Meta-Analyses (PRISMA) e buscas nas bases Pubmed, APA PsycNET, SciELO, ScienceDirect, Web of Science, BVS e LILACS. Foram analisados 17 estudos, permitindo observar aumento da flexibilidade psicológica, atenuação das taxas de abandono do tratamento e redução do consumo de substâncias nas intervenções analisadas.

Palavras-chave: drogas, terapia cognitiva, intervenção psicológica

\section{Terapia de Aceptación y Compromiso y Uso de Drogas: Una Revisión Sistemática}

Resumen: El uso nocivo de sustancias psicoactivas se ha considerado como uno de los mayores problemas de salud pública. Se utilizan varios enfoques para el tratamiento de los trastornos relacionados con el consumo de sustancias frente a los desafíos impuestos. Este estudio tuvo como objetivo identificar los trabajos empíricos que utilizaron ACT para el tratamiento del consumo de sustancias y sus respectivos resultados en cuanto a la aceptación, viabilidad y reducción de la gravedad de la dependencia, así como los resultados relacionados con las comorbilidades y otros aspectos asociados al uso, desde una revisión sistemática de la literatura sobre el tema y utilizando las recomendaciones de la guía Preferred Report Items for Systematic Reviews and Meta-Analyzes (PRISMA) y búsquedas en PubMed, APA PsycNET, SciELO, ScienceDirect, Web of Science, VHL y LILACS. Se analizaron 17 estudios, lo que permitió observar un aumento de la flexibilidad psicológica, una atenuación de las tasas de abandono del tratamiento y una reducción del consumo de sustancias en las intervenciones analizadas.

Palabras clave: drogas, terapia cognitiva, intervención psicológica

\footnotetext{
${ }^{1}$ Universidade Federal de Juiz de Fora, Juiz de Fora-MG, Brazil ${ }^{2}$ Universidade Federal do Rio de Janeiro, Rio de Janeiro-RJ, Brazil. ${ }^{3}$ Universidade Católica de Petrópolis, Petrópolis-RJ, Brazil

Article derived from de master's thesis of Mariana Fonseca Carvalho Maia under the guidance of Pollyanna Santos da Silveira, defended in 2020, in the Postgraduate Program in Psychology of the Universidade Federal de Juiz de Fora. Support: Financial support of FAPEMIG through the processes BPD-00678-14 and APQ03256-13 and scientific initiation scholarships CNPq, FCRM and FAPERJ. Correspondence adress: Pollyanna Santos da Silveira. Universidade Católica de Petrópolis. Rua Benjamin Constant, 213 - Centro, Petrópolis-RJ, Brazil. CEP 25.610-130. E-mail: pollyanna.silveira@ucp.br
}

The abusive and harmful use of drugs, as recognized today, has been considered one of the greatest public health issues, given its high and increasing magnitude (Capistrano et al., 2018). In 2016, about 271 million people aged from 15 to 64 years used some drug, out of which 35 million suffer from disorders arising from the use of these substances (United Nations Office on Drugs and Crime, 2019). Among the most relevant consequences of abusive use, neuropsychological, social, and health alterations are 
observed (Antunes \& Costa, 2019; Medeiros, Maciel, Sousa, Tenório-Souza, \& Dias, 2013). In addition to the increasing number of deaths, as reported in the 2019 World Drug Report, indicating 585,000 deaths and 42 million "healthy" years lost.

Several approaches, including psychological, multidisciplinary and drug therapies, are used for the treatment of substance-use disorder. A national survey conducted by Bastos, Vasconcellos, Boni, and Coutinho (2017) found that almost 1.6 million individuals aged from 12 to 65 years have received some of these treatments, at least once in their lives, corresponding to $1.1 \%$ of the Brazilian population. Despite the significant number, many challenges arise throughout the treatment, ranging from motivation to the influence of the services and approaches, which can directly affect the accession and remission of the disorder in a negative way, often resulting in premature desertion (Silveira, Tostes, Wan, Ronzani, \& Corrigan, 2018).

Considering the challenges imposed, several studies on new approaches have been carried out to ensure a more effective treatment with more comprehensive strategies in this scenario (Silveira et al., 2018). In this perspective, the Acceptance and Commitment Therapy (ACT) has been used, associated with common treatments, to reduce the severity of dependence and other comorbidities associated with the abuse of alcohol and other drugs (Kolling, Petry, \& Melo, 2011), for prevention and health promotion and to treat other disorders (Monteiro, Ferreira, Silveira, \& Ronzani, 2015).

A member of the group of Behavioral and Cognitive Therapies (Wilson, Bordieri, Flynn, Lucas, \& Slater, 2010), ACT was proposed by Steven Hayes and collaborators in the late 1980s (Hayes, 1987; Saban, 2015), but first systematized in the 1999 book entitled Acceptance and Commitment Therapy: An Experiential Approach to Behavior Change of Hayes, Strosahl and e Wilson. Its central aspect concerns psychological flexibility, characterized by the ability to contact with the present moment and accept private events, persisting in the search for clarification of personal values, which provides the emergence of actions towards them and, consequently, a more significant life (N. Costa, 2017; Hayes, 2019; Zhang et al., 2017).

The central intervention model of this approach encompasses six processes, namely: present moment, acceptance, values, actions with commitment, cognitive defusion, and the self as a context, which should be guided regarding the needs and characteristics of each individual (R.S. Costa \& Soares, 2015; Hayes, 2016). Acceptance concerns a voluntary process of openness, non-critical, observant, and flexible posture with experiences. The defusion reflects the process of language deliteralization, in the creation of nonliteral and non-evaluative contexts to weaken the relational contexts arising from the verbal and social community. Both processes work the aversive events and the conditions that lead the individual to seek help (Hayes et al., 2017, 2021).

Contact with the present moment reflects the individual's ability to be flexible and to live the experience at the very moment, intentionally alternating attention with focus and flexibility to the present. The self as a context encompasses the identification of distinct internal experiences of consciousness searching to become an observer of the stage where experiences, feelings, sensations, and thoughts happen (Hayes, 2016; Saban, 2015).

The values are understood as the quality of the action and operate as a compass in the construction of significant trajectories of a path to be followed. The action with commitment constitutes the expression of values in the construction of new goals, contexts and discovery or clarification of personal values that allow for the individual to identify possible paths, in the deliberate choice of behavior patterns (Hayes et al., 2021; Saban, 2015).

This study aimed to identify the empirical studies that used ACT for the treatment of substance use and their respective results regarding the acceptance, viability, and reduction of the severity of dependence, as well as the results related to comorbidities and other aspects associated with drugs use. Therefore, a systematic review of the literature was performed to provide an efficient scientific scope in order to meet the existing demands in the context of substance use dependence, analyzing at which points the ACT is effective and promising, considering the challenges encountered in this field.

\section{Method}

This systematic review was based on the recommendations in the Preferred Report Items for Systematic Reviews and Meta-Analyses (PRISMA) (Galvão, Pansani, \& Harrad, 2015) guide, focusing on the literature on ACT and substance use disorder. The bibliographic search was conducted in 2019 in the databases PubMed, PsycNET (APA), SciELO (Scientific Electronic Library Online), ScienceDirect, Web of Science, VHL (Virtual Health Library) and LILACS (Latin American and Caribbean Health Science Literature). Databases were selected considering their relevance in the indexing of scientific journals linked to the areas of knowledge assumed by this study, such as health and psychology.

As a search strategy, the descriptors "Substance-Related Disorders" and "Acceptance and Commitment Therapy" found from the vocabulary control method of the Medical Subject Heading Terms (Mesh Terms - MeSH), developed by the U.S. National Library of Medicine, were used in all databases. The two expressions were combined through the Boolean operator "AND" so that the intersecting fields between them were found, aiming to locate records where they occurred simultaneously.

As initial inclusion criteria, we established that the articles should be the result of an empirical research that: (a) evaluated the results of an intervention based on ACT and (b) focused on the treatment of substance use. Theoretical articles, literature review, editorials, among others were adopted as exclusion criteria.

In total, 53 articles were found based on electronic search in the databases and, after the exclusion of duplicate articles or unavailable for full reading, we obtained 40 articles. Articles dealing with systematic reviews and those that did not meet the initial inclusion criteria were excluded, totaling 17 articles to be full read and analyzed, a process that resulted in a total of 14 articles eligible for the review, showed in Figure 1. 
Articles identified by searches in PubMed, PsycINFO, SciELO, LILACS, Web of

Science, and VHL databases $(n=53)$

Articles after deleting duplicates and unavailable for full reading $(n=40)$

Articles reviewed by reading

titles and abstracts $(n=40)$
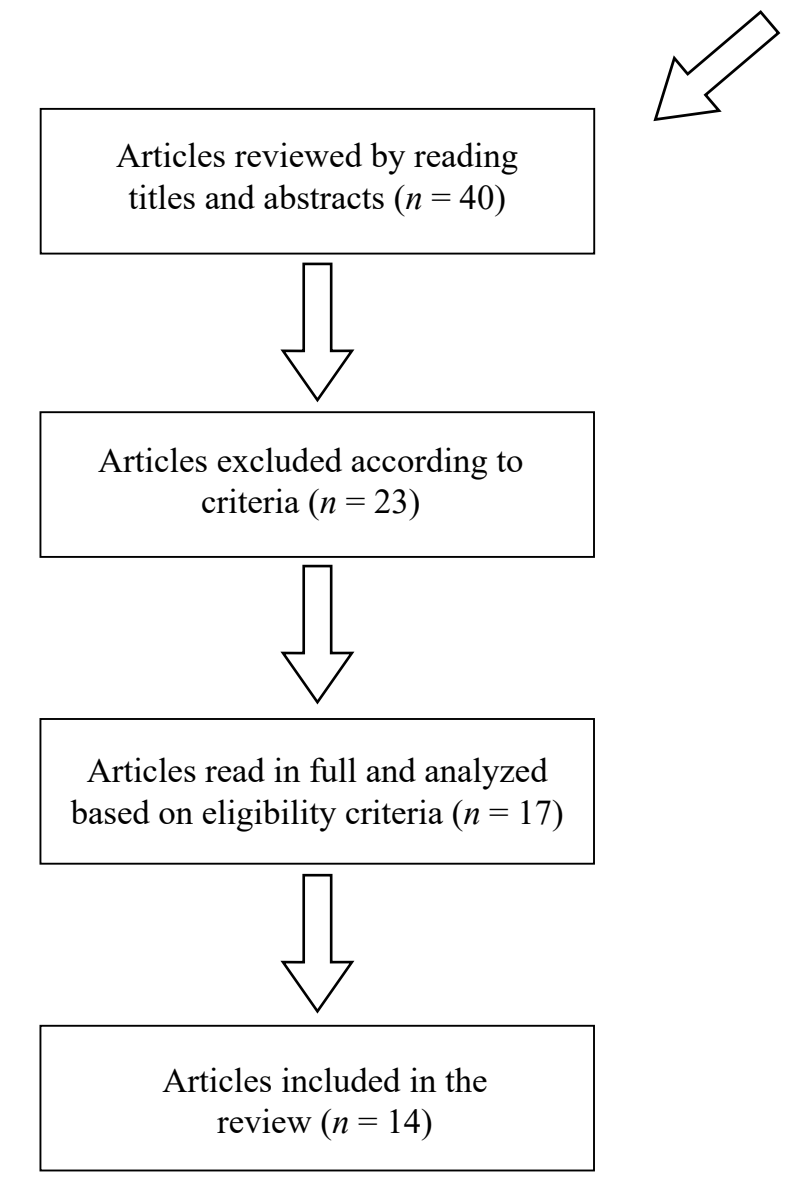

Figure 1. Procedures for identifying and selecting the studies included in the systematic review. Elaborated by the author.

\section{Results}

The resulting articles were analyzed based on three aspects: bibliometric indicators, method used, and main results. In the bibliometric indicators, the language, the country of origin of the articles and the year of publication were described. Regarding the method, we observed the type of design, target audience (contexts addressed, substances used, comorbidities), instruments used, and procedures (group or individual, face-to-face or remote). In the results of the studies, the observed changes, the effectiveness, feasibility and acceptability of the interventions were analyzed.

Among the 14 articles included in the analysis, 13 were published in English, only one in Spanish and, regarding the origin of the research, most articles were published in the United States, with 11 articles. In relation to the others, one was produced in China and two in Spain. The first article was published in 2011 and, since then, at least one article has been published until 2017, the largest number in 2015, a period that involved greater dissemination of the subject in scientific publications among the articles analyzed, with a six publications. Most studies used the quantitative approach in the analysis of their data (85.71\%) and a small portion used quantitative/qualitative methods in the same study (14.29\%), with none of the approach exclusively qualitative.

The populations studied showed remarkable variability regarding sample size, from 1 to 420 participants (Table 1). Most studies involved adults of both sexes (64.29\%), and only $14.29 \%$ investigated only women, $7.14 \%$ investigated male older adults, $7.14 \%$ adolescents of both sexes and $7.14 \%$ adult males. The contexts were diverse: incarcerated populations $(14.29 \%)$, in stable and long-term mental health treatment for comorbid Post Traumatic Stress Disorder (PTSD) $(7.14 \%)$, undergoing drug treatment for comorbid Bipolar Disorder $(7.14 \%)$, in residential treatment for substance use disorder (14.29\%), in primary health care centers (7.14\%), undergoing treatment for chronic pain (7.14\%), in a treatment program integrated to hospitalization in a university 
hospital $(7.14 \%)$, inserted in a treatment program for the use of substances in adolescents (7.14\%) and without concomitant treatment criterion or prior to interventions $(28.58 \%)$.

The main drugs found in the reviewed articles were tobacco $(43 \%)$ and substance use in general (42.86\%), alcohol (7.14\%), and opiates (7.14\%). Comorbidities related to drug use disorder were present in half of the articles. The most evident disorders were bipolar affective disorder (BAD) $(14.29 \%)$ and depression $(14.29 \%)$, themes that were also addressed simultaneously in one of the articles, in addition to PTSD (7.14\%), mental disorders in general (7.14\%), and neuropsychological comorbidities (7.14\%). In addition to comorbidities, one study investigated the shame associated with substance abuse and another aimed to investigate opioid dependence in cases of chronic pain.
The central constructs for this systematic review were evaluated in the research through standardized instruments and scales, as well as interviews that aimed to evaluate the change in psychological flexibility, experiential acceptance, anxiety and depression levels, treatment adhering, the degree of severity of dependence, behavior change, among others. Pre- and post-test were performed, and some studies prolonged the follow-up with the replication of the instruments one, three, or six months after the intervention. The analyzed studies did not describe the eligibility criteria for the instruments used and most used three or more items, except for Zeng, Heffner, Copeland, Mull and Bricker (2016) who used only one, as described in Table 1.

Table 1

Population analysis, objectives and instruments of the articles

\begin{tabular}{|c|c|c|c|}
\hline Articles & Population $(n)$ & Objectives & Instruments \\
\hline $\begin{array}{l}\text { Luoma, Kohlenberg, Hayes and } \\
\text { Fletcher (2011) }\end{array}$ & $\begin{array}{l}\text { Program participants } \\
(n=133)\end{array}$ & $\begin{array}{l}\text { Assess ACT for reducing shame in } \\
\text { substance users }\end{array}$ & $\begin{array}{l}\text { ISS; TSR; TLFB; The General Health } \\
\text { Questinnaire- 12; The Quality of Life } \\
\text { Scale; The Multidimentional Scale of } \\
\text { Perceveid Social Support. }\end{array}$ \\
\hline $\begin{array}{l}\text { Litvin, Kovacs, Hayes and } \\
\text { Brandon (2012) }\end{array}$ & Adult smokers $(n=162)$ & $\begin{array}{l}\text { Compare ACT to suppression } \\
\text { technique }\end{array}$ & $\begin{array}{l}\text { FTND; QSU-4; Single item urgency scale; } \\
\text { Magnitude estimate of desire. }\end{array}$ \\
\hline $\begin{array}{l}\text { Villagrá Lanza \& Gonzáles- } \\
\text { Menéndez (2013) }\end{array}$ & $\begin{array}{l}\text { Incarcerated women } \\
(n=31)\end{array}$ & $\begin{array}{l}\text { Test the effectiveness of ACT in the } \\
\text { treatment of substance use disorders }\end{array}$ & $\begin{array}{l}\text { Interview ad hac; MINI International } \\
\text { Neuropsychiatric Interview; ASI-6; Anxiety } \\
\text { sensitivity index; AAQ-II; AU; Auto save. }\end{array}$ \\
\hline $\begin{array}{l}\text { Villagrá Lanza, Fernández } \\
\text { García, Rodríguez Lamelas and } \\
\text { González-Menéndez (2014) }\end{array}$ & $\begin{array}{l}\text { Incarcerated women } \\
(n=50)\end{array}$ & $\begin{array}{l}\text { Determine the differential efficacy } \\
\text { of ACT and CBT in substance use } \\
\text { disorders }\end{array}$ & $\begin{array}{l}\text { ASI-6; MINI Internacional Neuropsychiatric } \\
\text { Interview; ASI; AAQ-II; UA; Auto save. }\end{array}$ \\
\hline Kelly et al. (2015) & $\begin{array}{l}\text { Smokers undergoing } \\
\text { drug treatment for } \\
\text { bipolar disorder and } \\
\text { smoking }(n=19)\end{array}$ & $\begin{array}{l}\text { Evaluation of the viability and } \\
\text { acceptance of ACT-TP combined } \\
\text { with nicotine patches }\end{array}$ & $\begin{array}{l}\text { Structured clinical interview for the non- } \\
\text { patient version of the DSM-IV; FTND; } \\
\text { The scale of contemplation; CSQ-8; QSU- } \\
\text { Brief; Self report. }\end{array}$ \\
\hline Marín Romero (2015) & $\begin{array}{l}\text { Adult multi-drug user } \\
(n=1)\end{array}$ & $\begin{array}{l}\text { ACT-based intervention in } \\
\text { conjunction with neuropsychological } \\
\text { rehabilitation to reduce substance use }\end{array}$ & $\begin{array}{l}\text { AAQ-II; ISP; SCL-90-R Symptoms } \\
\text { Inventory; MoCA; VinciDrog. }\end{array}$ \\
\hline Thekiso et al. (2015) & $\begin{array}{l}\text { Hospital patients with } \\
\text { comorbid affective } \\
\text { disorder }(n=52)\end{array}$ & $\begin{array}{l}\text { Examine the effectiveness of ACT } \\
\text { added to the usual treatment }\end{array}$ & TLFB; BDI; BAI; YMRS \\
\hline Mak, Lee e Loke (2015) & $\begin{array}{l}\text { Smoking patients in } \\
\text { Primary Care Centers } \\
(n=420)\end{array}$ & $\begin{array}{l}\text { Explore factors related to participation } \\
\text { in an ACT-based program }\end{array}$ & SF-12; FTND; ERQ \\
\hline $\begin{array}{l}\text { Heffner, McClure, Mull, } \\
\text { Anthenelli e Bricker (2015) }\end{array}$ & $\begin{array}{l}\text { Group Health members } \\
\text { daily smokers with } \\
\text { bipolar disorder }(n=16)\end{array}$ & $\begin{array}{l}\text { Develop and test new smoking } \\
\text { cessation intervention by combining } \\
\text { ACT with the use of nicotine patches }\end{array}$ & $\begin{array}{l}\text { Semi-structured assessment protocol for the } \\
\text { genetics of alcoholism; YMRS; MADRS; } \\
\text { MINI International Neuropsychiatric } \\
\text { Interview; PHQ-9; ASRM }\end{array}$ \\
\hline Jones et al. (2015) & $\begin{array}{l}\text { General population of } \\
\text { smokers }(n=94)\end{array}$ & $\begin{array}{l}\text { Compare the receptivity of treatment } \\
\text { with ACT with a government } \\
\text { program via web }\end{array}$ & $\begin{array}{l}\text { Anxiety and Depression Detector; } \\
\text { AIS-27; Satisfaction questionnaire. }\end{array}$ \\
\hline Zeng et al. (2016) & $\begin{array}{l}\text { General population of } \\
\text { smokers }(n=84)\end{array}$ & $\begin{array}{l}\text { Examine a smoking cessation app } \\
\text { based in the ACT }\end{array}$ & AIS-27 \\
\hline $\begin{array}{l}\text { Smallwood, Potter e Robin } \\
\text { (2016) }\end{array}$ & $\begin{array}{l}\text { Patients with chronic low } \\
\text { back pain }(n=12)\end{array}$ & $\begin{array}{l}\text { Assess ACT in relation to pain and } \\
\text { opioid dependence }\end{array}$ & $\begin{array}{l}\text { AAQ-II; MAAS; RMDQ; Ten Point (0-9); } \\
\text { SPM8. }\end{array}$ \\
\hline $\begin{array}{l}\text { Thurstone, Hull, Timmerman } \\
\text { and Emrick (2017) }\end{array}$ & $\begin{array}{l}\text { Adolescents in substance } \\
\text { use treatment program } \\
(n=41)\end{array}$ & $\begin{array}{l}\text { Intervention with Motivational } \\
\text { Interview/ACT for the treatment of } \\
\text { substance use, evaluating its viability }\end{array}$ & ORS; TLFB; SRS \\
\hline Shorey et al. (2017) & $\begin{array}{l}\text { Residential substance } \\
\text { use treatment program } \\
(n=117)\end{array}$ & $\begin{array}{l}\text { Verify the effectiveness of Mindfulness } \\
\text { and ACT-based interventions in } \\
\text { relation to the usual treatment }\end{array}$ & PACS; FFMQ; AAQ-AS \\
\hline
\end{tabular}


The sample analyzed presented interventions based on ACT in group context $(50 \%)$ or individual $(50 \%)$, in faceto-face $(64.29 \%)$ or distance $(35.71 \%), 21.42 \%$ of them via the telephone call, $7.14 \%$ via internet, and $7.14 \%$ via a smartphone software app. The interventions were performed as an additive for conventional treatment for dependence on tobacco, alcohol, and other drugs in different contexts: primary health care, hospitalization programs, incarceration (prisons), comorbidities in mental health, among others (Jones et al., 2015; Smallwood et al., 2016; Thurstone et al., 2017; Villagrá Lanza \& González-Menéndez, 2013).

The articles aimed the contributions of ACT in the treatment of substance use, verifying the feasibility of the intervention, the acceptance of participants, the effectiveness of the combined ACT or in contrast to other types of approaches, the adhering to the use of ACT-based technological tools for cessation of substance use, the efficacy for the reduction of chronic pain and internalized shame and comorbid disorders.

The effects originated from the use of ACT were evidenced in different ways - depending on the study - the context and the intended objectives. Generally, most studiesindicated an overlap of ACT in relation to other approaches to substance use disorder, high potential in some combinations, increased acceptance, greater psychological flexibility, effectiveness in reducing and desiring to use substances, promoting relapse prevention, increased adherence to treatment, increased confidence and motivation, and reduction of symptoms of comorbidities related to the use of alcohol and other drugs, such as anxiety and depression levels, symptomatological declines in PTSD and neuropsychological deterioration (Litvin et al., 2012; Marín Romero, 2015; Smallwood et al., 2016; Thurstone et al., 2017; Villagrá Lanza et al., 2014).

The efficacy of ACT in relation to reduction or abstinence from drug use was reported in $64.29 \%$ of the studies, which addressed tobacco consumption, alcohol, cocaine, marijuana, opiates, and substance use in general (Heffner et al., 2015; Kelly et al., 2015; Luoma et al., 2011; Marín Romero, 2015; Smallwood et al., 2016; Thekiso et al., 2015; Thurstone et al., 2017; Villagrá Lanza et al., 2014; Villagrá Lanza \& González-Menéndez, 2013).

When compared to cognitive behavioral therapy (CBT) and Suppression Techniques, advantages of ACT were presented in relation to the former, but no greater efficacy was evidenced in relation to the second. In the post-test and follow-up results, the participants of the ACT group presented statistically significant, higher, and increasing abstinence rates, in relation to the CBT group, in addition to the progressive decreases in all areas of dependence severity (Villagrá Lanza et al., 2014). In relation to the suppression technique, in the experimental study conducted by Litvin et al. (2012), although the ACT and suppression groups showed greater self-efficacy to avoid smoking behavior compared to the control group, there was no evidence of superiority of ACT in relation to the other approach.

In combination with other approaches, despite limitations, studies by Shorey et al. (2017) and Thurstone et al. (2017), which combined ACT, respectively, with "Entrevista
Motivacional e ao Mindfulness" (Motivational Interview and Mindfulness), indicated promising results of these combinations. The first showed significant differences in the scale of evaluation of the results in relation to the emotional well-being of the participants between the pre- and the posttest, presenting high rates of abstinence for at least one week among the participants, as well as high satisfaction with the intervention model, factors that suggest greater involvement of young people in treatment and consequent reduction of the rate of premature deserting of care (Thurstone et al., 2017). In the study by Shorey et al. (2017), without finding statistically significant differences, indicated a lower desire for drug use and greater psychological flexibility compared to the usual treatment group.

Regarding studies that investigated comorbidities related to substance use, there was a variability in terms of the type of comorbid disorder, environment in which the intervention occurred and in the number and form of participants distribution, however, most of them indicated to the benefits of ACT for the reduction of comorbid symptoms (Jones et al., 2015; Kelly et al., 2015; Marín Romero, 2015; Thekiso et al., 2015; Villagrá Lanza \& González-Menéndez, 2013). The research involving individuals with PTSD and tobacco dependence showed a significant reduction in PTSD symptoms over time and that, although abstinence levels from tobacco increased from the beginning of treatment to the one-month follow-up, there was a reduction in the six-month follow-up (Kelly et al., 2015).

The case study with individuals with neuropsychological comorbidities conducted by Marín Romero (2015) showed a clear reduction in problems related to the prefrontal cortex, especially in the areas involved with executive control, attention problems, and social behavior, in addition to the increase in the behavioral repertoire.

In comorbidities with affective disorders, the studies by Jones et al. (2015) and Thekiso et al. (2015) suggest that the use of ACT may lead to a sustained improvement in the reduction of comorbid disorders. Thekiso et al. (2015) indicated lower scores in depression intensity and obsessive-compulsive behaviors in alcohol desire and significant statistical differences in anxiety reduction, although in relation to total abstinence rates, there were no significant differences between the ACT and usual treatment groups. However, Heffner et al. (2015) did not find significant clinical changes in relation to affective disorder from baseline to the end of treatment, although they observed high receptivity to the intervention by participants, in addition to the effects on smoking cessation. Villagrá Lanza and González-Menéndez (2013), in the study with incarcerated women, also observed a series of comorbid disorders related to substance use disorder and, in the tests immediately after the intervention and in the six-month follow-up, found a reduction mainly in anxiety symptoms, decreased experiential avoidance and increased acceptance, in addition to the reduced drug use.

Similarly, when investigating the shame associated with substance use disorder, Luoma et al. (2011) recorded longer periods of abstinence, reduced levels of internalized shame, 
and lower rates of deterioration in participants who received the intervention. Also, the study by Smallwood et al. (2016) with patients with chronic pain and opioid dependence, showed efficient results for the reduction of pain triggering and consequent reduction of drug use.

Finally, the studies that investigated adherence and receptivity to interventions via telephone call, internet, and mobile software app, based on the ACT aimed to smoking cessation, although only one of them found significant differences between the groups for smoking cessation or reduction, all indicated high receptivity and a higher probability of adherence, in addition to relating the increase in acceptance levels with greater benefits in treatment (Heffner et al., 2015; Jones et al., 2015; Mak et al., 2015; Zeng et al., 2016). The summation of the main aspects of these studies is as follows:

Table 2

Analysis of the main aspects

\begin{tabular}{lc}
\hline Aspect & Result \\
\hline Method & Number of Publications / (\%) \\
\hline Type of design & $12 /(85.71)$ \\
Quantitative & $02 /(14.29)$ \\
Qualitative/Quantitative & $01 /(7.14 \%)$ \\
\hline Target Audience: & $09 /(64.29 \%)$ \\
Population: & $02 /(14.29 \%)$ \\
Teens of both sexes & $01 /(7.14 \%)$ \\
Adults of both sexes & $01 /(7.14 \%)$ \\
Women & \\
Men &
\end{tabular}

Drugs evidenced

$\begin{array}{lc}\text { Alcohol } & 01 /(7.14 \%) \\ \text { Tobacco } & 06 /(42,86 \%) \\ \text { Opiates } & 01 /(7.14 \%) \\ \text { Drugs in general } & 06 /(42,86 \%)\end{array}$

Comorbidities

Neuropsychological comorbidities

Depression

$01 /(7.14 \%)$

Bipolar Affective Disorder (BAD)

$02 /(14.29 \%)$

Posttraumatic Stress Disorder (PTSD)

$02 /(14.29 \%)$

Mental disorders in general

$01 /(7.14 \%)$

No disorder identified

$01 /(7.14 \%)$

$07 /(50.00 \%)$

Procedures
Individual
Grupal
Face-to-face mode
Distance mode
Via phone
Via web
Via smartphone app
Random distribution
Control group
Pre-test
Post-test

$07 /(50.00 \%)$

$07 /(50.00 \%)$

$09 /(64.29 \%)$

$05 /(35.71 \%)$

$03 /(21.42 \%)$

$01 /(7.14 \%)$

$01 /(7.14 \%)$

09 / $(64.29 \%)$

$08 /(57,12 \%)$

$12 /(85.71 \%)$

$09 /(64.29 \%)$

\section{Main Results}

Effectiveness of ACT in relation to the reduction of drug use Increased acceptance and psychological flexibility

09 / (64.29\%)

Effectiveness in reducing the desire to use substances and greater adherence to treatment $05 /(35.71 \%)$ Increased confidence, motivation and reduction of comorbidities related to substance use $05 /(35.71 \%)$ Reduction of comorbid symptoms High receptivity, increased probability of adherence and the levels of acceptance based on the benefits $05 /(35.71 \%)$ of treatment 


\section{Discussion}

Although the ACT emerged as a proposal in the late 1980s, this review observed publications of empirical studies on substance use disorders only from 2011. Generally, the analyzed studies used ACT as an additional approach to the usual treatment for substance dependence, presenting it as a positive differential in the various types of intervention, indicating, especially, to increase psychological flexibility, greater engagement in treatment, reduction of symptomatology of comorbid disorders and substance use (Heffner et al., 2015; Kelly et al., 2015; Luoma et al., 2011; Marín Romero, 2015; Shorey et al., 2017; Smallwood et al., 2016; Thekiso et al., 2015; Villagrá Lanza et al., 2014; Villagrá Lanza \& González-Menéndez, 2013).

Based on the observations of the studies it was possible to verify that they are consistent with the characteristics of the population. Most studies identified comorbidities related to substance use disorder and that, even with a range of treatments available, we can still observe little adherence to them. Many people, when starting this type of treatment, often choose to finish it prematurely, thus leaving evidenced the impacts of abuse or substance dependence, factors that present the need for new approaches in this context as evidenced in some studies (Heffner et al., 2015; Jones et al., 2015; Thurstone et al., 2017).

Considering these observations, we emphasize the significance of discussing the important aspects from the articles analyzed, such as the models of treatments aimed at the adolescent public, which highlight some weaknesses and also indicate the relevance of understanding the aspects that enhance adherence, including aspects such as the ability to express themselves openly and honestly, involvement with goal setting, and motivation for change (Thurstone et al., 2017). Besides, the scarcity of approaches directed at individuals who use substances and have some comorbidity reiterates this precariousness, evidencing that the insufficiency of integrated treatments is a problematic aspect, due to most people undergoing treatment for substance abuse present psychiatric disorders concomitantly and, consequently, worse results in relation to treatment and greater difficulty in their treatment (Jones et al., 2015; Thurstone et al., 2017; Villagrá Lanza \& González-Menéndez, 2013).

In this sense, as presented in the research, ACT has been gaining visibility and proving to be effective among the modalities of therapies associated with treatment for substance use disorder, since it is intended to increase psychological flexibility, presenting a model of functioning along a continuum, cultivating processes during treatment, and preventing psychological difficulties in the future (Wilson, Schnetzer, Flynn, \& Kurz, 2012), which may lead to promising long-term results, as verified in follow-up studies (Heffner et al., 2015; Jones et al., 2015; Kelly et al., 2015; Luoma et al., 2011; Marín Romero, 2015; Thekiso et al., 2015; Villagrá Lanza et al., 2014; Villagrá Lanza \& González-Menéndez, 2013; Zeng et al., 2016). Moreover, to what ACT proposes, the psychological flexibility model is transdiagnostic, which means that it is able to identify common mechanisms underlying a series of psychological difficulties, proving to be more effective and efficient to address the problem of comorbidities aforementioned, that is common in substance use disorders, whose comorbidity rates are quite high (Grant et al., 2004), a factor that is consistent with the results of studies that indicate a reduction in the symptomatology of comorbidities associated with the disorder (Kelly et al., 2015; Marín Romero, 2015; Smallwood et al., 2016; Thekiso et al., 2015; Villagrá Lanza et al., 2014; Villagrá Lanza \& González-Menéndez, 2013).

Several authors also described the existence of a body of evidence suggesting the misuse of substances as a form of experiential avoidance (Luoma et al., 2011; Marín Romero, 2015; Thekiso et al., 2015). On the other hand, ACT works on issues related to acceptance mechanisms, whose objective is to provide a more significant change, providing a more effective treatment to people with substance dependence, which may suggests the improvements evidenced in the reviewed articles, in which the interventions based on the ACT allowed the target audience to present, at the end of them, greater psychological flexibility and a more meaningful perspective of life through trust, respect and support, articulating their lives in a more active and more conscious way, with open contact with present in development (Villagrá Lanza et al., 2014; Villagrá Lanza \& González-Menéndez, 2013).

Although the articles indicated satisfactory results favoring ACT, limitations were verified in the possibilities of generalization of the same, as well as in their own effectiveness, due to part of the studies did not have a number of participants and type of sampling representative, which hinders the generalization for other groups, reducing their external validity (Heffner et al., 2015; Kelly et al., 2015; Thurstone et al., 2017). Regarding internal validity, the absence of randomization (Heffner et al., 2015; Kelly et al., 2015; Thurstone et al., 2017; Zeng et al., 2016) and the reduced number of participants (Heffner et al., 2015; Kelly et al., 2015; Villagrá Lanza \& González-Menéndez, 2013) also place themselves as limitations in the process of significant differentiation between treatment groups. The possibility of contamination among the groups from the sharing of the experiences of participants who were already inserted in the same mental health treatment should also be considered as a possible influence rife of the results in studies with this condition, such as Shorey et al. (2017).

Another limitation of the studies included is that five (38\%) of them did not evaluate the long-term results, beyond the period immediately after the intervention. Despite the post-test, observe the maintenance or not of the benefits in the medium and long term in these studies was impossible, remaining the effects in these periods widely unknown (Litvin et al., 2012; Mak et al., 2015; Shorey et al., 2017; Smallwood et al., 2016; Thurstone et al., 2017).

Although most studies have adopted validated instruments, which confer higher reliability in terms of the ability and measure with efficiency, the triangulation of methods was scarce. Most of them used standardized 
instruments to verify aspects related to drug pattern and consumption, anxiety and depression levels, acceptance and psychological flexibility, however, interviews and focus groups, as well as other methods, could help, essentially, the evaluation of changes in the indicators of viability, acceptability and satisfaction with the intervention. Among the limitations of the studies recognized by the authors, we can consider the existence of self-report measures, subject to the effects of demand and expectation of the participants, which also confers limitations on the results, as demonstrated in the study by Litvin et al. (2012).

Some limitations of the review process should also be mentioned in this study. Although all the recommendations of the PRISMA protocol have been used, other studies that meet the inclusion criteria may not have been identified, both according to the search strategy and the terms used, as well as those used to index the studies of interventions performed by other authors to the databases.

This systematic review provides information on the scientific production regarding the use of ACT in the context of substance use disorders, and positive effects resulting from interventions are observed, including increased psychological flexibility, significant improvement in issues related to experiential control, attenuation of treatment abandonment rates and reduction of substance use, as well as the improvement in the quality of life of patients with comorbidities related to chronic pain and progressive decrease in anxiety and depressive symptomatology. In view of the existence of few studies related to the subject, the low effectiveness and low retention of the existing treatments, these findings demonstrate that further investigations regarding the use of this approach are essential, aiming to obtain subsidies to prove its effectiveness, as well as the feasibility of an integral and efficient model that can positively impact the treatment for addiction.

\section{References}

Antunes, A., \& Costa, E. C. V. (2019). Sono, agressividade e comportamentos de risco em indivíduos dependentes de drogas e de álcool [Sleep, aggressiveness and risk behaviors in individuals dependent on drugs and alcohol]. Análise Psicológica, 37(1), 1-14. doi:10.14417/ap.1390

Bastos, F. I. P. M., Vasconcellos, M. T. L., Boni, R. B., \& Coutinho, C. F. S (2017). III Levantamento Nacional sobre o uso de drogas pela população brasileira [III National Survey on drug by the Brazilian population]. Rio de Janeiro, RJ: FIOCRUZ/ICICT. Retrieved from https://www.arca.fiocruz.br/bitstream/icict/34614/2/ III\%20LNUD_ENGLISH.pdf

Capistrano, F. C., Maftum, G. J., Mantovani, M. F., Felix, J. V. C., Kalinke, L. P., Nimtz, M. A., \& Maftum, M. A. (2018). Consequências do uso abusivo de substâncias psicoativas por pessoas em tratamento [Consequences of the abuse of psychoactive substances by people undergoing treatment]. Saúde e Pesquisa, 11(1), 17-26. doi:10.17765/1983-1870.2018v11n1p17-26
Costa, N. (2017). Terapia de aceitação e compromisso: É uma proposta de intervenção cognitivista? [Acceptance and commitment therapy: Is it a cognitive intervention proposal?]. Perspectivas em Análise do Comportamento, 3(2), 117-126. doi:10.18761/perspectivas.v3i2.233

Costa, R. S., \& Soares, M. R. Z. (2015). Terapia de aceitação e compromisso: O sofrimento psicológico em um caso clínico [Acceptance and commitment therapy: Psychological suffering in a clinical case]. Psicologia: Teoria e Prática, 17(3), 19-27. doi:10.15348/1980-6906/psicologia.v17n3p19-27

Galvão, T. F., Pansani, T. S. A., \& Harrad, D. (2015). Principais itens para relatar revisões sistemáticas e metaanálises: A recomendação PRISMA [Main items to report systematic reviews and meta-analyzes: The PRISMA recommendation]. Epidemiologia e Serviços de Saúde, 24(2),335-342. doi:10.5123/S1679-49742015000200017

Grant, B. F., Stinson, F. S., Dawson, D. A., Chou, S. P., Dufour, M. C., Compton, W., ... Kaplan, K. (2004). Prevalence and co-occurrence of substance use disorders and independent mood and anxiety disorders: Results from the National Epidemiologic Survey on Alcohol and Related Conditions. Archives of General of Psychiatry, 61(8), 807-816. doi:10.1001/archpsyc.61.8.807

Hayes, S. C. (1987). A contextual approach to therapeutic change. In N. S. Jacobson (Ed.), Psychotherapists in clinical practice: Cognitive and behavioral perspectives (pp. 327-387). New York, NY: Guilford.

Hayes, S. C. (2016). Acceptance and commitment therapy, relational frame theory, and the third wave of behavioral and cognitive therapies. Behavior Therapy, 47(6), 869-885. doi:10.1016/j.beth.2016.11.006

Hayes, S. C. (2019). Acceptance and commitment therapy: Towards a unified model of behavior change. World Psychiatry, 18(2), 226-227. doi:10.1002/wps.20626

Hayes, S. C., Strosahl, K. D., \& Wilson, K. G. (1999). Acceptance and commitment therapy: An experiential approach to behavior change. New York, NY: Guilford.

Hayes, S. C., Strosahl, K. D., \& Wilson, K. G. (2021). Terapia de aceitação e compromisso: $O$ processo e a prática da mudança consciente [Acceptance and commitment therapy: The process and practice of conscious change] (S. M. M. Rosa, Trans., 2nd ed.). Porto Alegre, RS: Artmed.

Heffner, J. L., McClure, J. B., Mull, K. E., Anthenelli, R. M., \& Bricker, J. B. (2015). Acceptance and commitment therapy and nicotine patch for smokers with bipolar disorder: Preliminary evaluation of in-person and telephone-delivered treatment. Bipolar Disorders, 17(5), 560-566. doi:10.1111/bdi.12300

Jones, H. A., Heffner, J. L., Mercer, L., Wyszynski, C. M., Vilardaga, R., \& Bricker, J. B. (2015). Web-based acceptance and commitment therapy smoking cessation treatment for smokers with depressive symptoms. Journal of Dual Diagnosis, 11(1), 56-62. doi:10.1080/15504263.2014.992588 
Kelly, M. M., Sido, H., Forsyth, J. P., Ziedonis, D. M., Kalman, D., \& Cooney, J. L. (2015). Acceptance and commitment therapy smoking cessation treatment for veterans with posttraumatic stress disorder: A pilot study. Journal of Dual Diagnosis, 11(1), 50-55. doi:10.1080/15504263.2014.992201

Kolling, N. M., Petry, M., \& Melo, W. V. (2011). Outras abordagens no tratamento da dependência do crack [Other treatment approaches for crack dependence]. Revista Brasileira de Terapias Cognitivas, 7(1), 7-14. http://pepsic. bvsalud.org/scielo.php?script $=$ sci_arttext\&pid=S1808$56872011000100003 \& \operatorname{lng}=$ pt\&nrm $=$ iso\&tlng $=$ pt

Litvin, E. B., Kovacs, M. A., Hayes, P. L., \& Brandon, T. H. (2012). Responding to tobacco craving: Experimental test of acceptance versus suppression. Psychology of Addictive Behaviors, 26(4), 830-837. doi:10.1037/a0030351

Luoma, J. B., Kohlenberg, B. S., Hayes, S. C., \& Fletcher, L. (2011). Slow and steady wins the race: A randomized clinical trial of acceptance and commitment therapy targeting shame in substance use disorders. Journal of Consulting and Clinical Psychology, 80(1), 43-53. doi: $10.1037 / \mathrm{a} 0026070$

Mak, Y. W., Lee, P. H., \& Loke, A. Y. (2015). Predictors of participation in a telephone-based acceptance and commitment therapy for smoking cessation study. $B M C$ Public Health, 15(1), 1288. doi:10.1186/s12889-015-2650-0

Marín Romero, B. (2015). Tratamiento mediante ACT en un caso de conductas adictivas con sintomatología prefrontal [Treatment by ACT in a case of addictive behaviors with prefrontal symptoms]. Apuntes de Psicología, 33(3), 117-126. Retrieved from https://idus. us.es/bitstream/handle/11441/85145/568-1288-1-SM. pdf? sequence $=1$ \&isAllowed $=\mathrm{y}$

Medeiros, K. T., Maciel, S. C., Sousa, P. F., Tenório-Souza, F. M., \& Dias, C. C. V. (2013). Representações sociais do uso e abuso de drogas entre familiares de usuários [Social representations of drug use and abuse among family members of users]. Psicologia em Estudo, 18(2), 269-279. Retrieved from https://www.scielo.br/j/pe/a/ MGGG5R3MMmszKjgjn8D5NqH/?lang=pt

Monteiro, E. P., Ferreira, G. C. L., Silveira, P. S., \& Ronzani, T. M. (2015). Acceptance and commitment therapy (ACT) and stigma: A narrative review. Revista Brasileira de Terapias Cognitivas, 11(1), 25-31. doi:10.5935/1808-5687.20150004

Shorey, R. C., Elmquist, J., Gawrysiak, M. J., Strauss, C., Haynes, E., Anderson, S., \& Stuart, G. L. (2017). A randomized controlled trial of a mindfulness and acceptance group therapy for residential substance use patients. Substance Use \& Misuse, 52(11), 1400-1410. doi:10.1080/10826084.2017.1284232

Saban, M. T. (2015). Introdução à terapia de aceitação e compromisso [Introduction to acceptance and commitment therapy] (2nd ed.). Belo Horizonte, MG: Artesã.
Silveira, P. S., Tostes, J. G. A., Wan, H. T., Ronzani, T. M., \& Corrigan, P. W. (2018). The stigmatization of drug use as mechanism of legitimation of exclusion. In T. M. Ronzani (Ed.), Drugs and social context: Social perspectives on the use of alcohol and other drugs (pp. 15-25). Cham, Switzerland: Springer.

Smallwood, R. F., Potter, J. S., \& Robin, D. A. (2016). Neurophysiological mechanisms in acceptance and commitment therapy in opioid-addicted patients with chronic pain. Psychiatry Research: Neuroimaging, 250, 12-14. doi:10.1016/j.pscychresns.2016.03.001

Thekiso, T. B., Murphy, P., Milnes, J., Lambe, K., Curtin, A., \& Farren, C. K. (2015). Acceptance and commitment therapy in the treatment of alcohol use disorder and comorbid affective disorder: A pilot matched control trial. Behavior Therapy, 46(6), 717-728. doi:10.1016/j. beth.2015.05.005

Thurstone, C., Hull, M., Timmerman, J., \& Emrick, C. (2017). Development of a motivational interviewing/acceptance and commitment therapy model for adolescent substance use treatment. Journal of Contextual Behavioral Science, 6(4), 375-379. doi:10.1016/j.jcbs.2017.08.005

United Nations Office on Drugs and Crime. (2019). World Drug Report 2019. New York, NY: Author. Retrieved from https://wdr.unodc.org/wdr2019/en/index.html

Villagrá Lanza, P., Fernández García, P., Rodríguez Lamelas, F., \& González-Menéndez, A. (2014). Acceptance and commitment therapy versus cognitive behavioral therapy in the treatment of substance use disorder with incarcerated women: Drug abuse treatments to incarcerated women. Journal of Clinical Psychology, 70(7), 644-657. doi:10.1002/jclp.22060

Villagrá Lanza P., \& González-Menéndez, A. (2013). Acceptance and commitment therapy for drug abuse in incarcerated women. Psicothema, 25(3), 307-312. doi:10.7334/psicothema2012.292

Wilson, K. G., Bordieri, M. J., Flynn, M. K., Lucas, N. N., \& Slater, R. M. (2010). Understanding acceptance and commitment therapy in context: A history of similarities and differences with other cognitive behavior therapies. In J. D. Herbert \& E. M. Forman (Eds.), Acceptance and mindfulness in cognitive behavior therapy: Understanding and applying the new therapies (pp. 233-263). Hoboken, NJ: Wiley.

Wilson, K. G., Schnetzer, L., Flynn, M. K., \& Kurz, A. S. (2012). Treating substance abuse with acceptance and commitment therapy. In S. C. Hayes \& M. E. Levin (Eds.), Acceptance, mindfulness, values, and addictive behaviors: Counseling with contemporary cognitive behavioral therapies (pp. 27-68). Oakland, CA: New Harbinger. 
Zeng, E. Y., Heffner, J. L., Copeland, W. K., Mull, K. E., \& Bricker, J. B. (2016). Get with the program: Adherence to a smartphone app for smoking cessation. Addictive Behaviors, 63, 120-124. doi:10.1016/j. addbeh.2016.07.007

Zhang, C. Q., Leeming, E., Smith, P., Chung, P. K., Hagger, M. S., \& Hayes, S. C. (2017). Acceptance and commitment therapy for health behavior change: A contextually-driven approach. Frontiers in Psychology, 8, 2350. doi:10.3389/fpsyg.2017.02350

Mariana Fonseca Carvalho Maia has a Master's degree in Psychology at the Universidade Federal de Juiz de Fora, Juiz de Fora-MG, Brazil.

Bruna Ferreira dos Santos is a Master's candidate of the Postgraduate, Program in Psychology at Universidade Federal do Rio de Janeiro, Rio de Janeiro-RJ, Brazil.

Lorrainy Costa de Castro is a Master's candidate of the Postgraduate Program in Psychology at Universidade Federal do Rio de Janeiro, Rio de Janeiro-RJ, Brazil.

Natália São Tiago Vieira is a Master's candidate of the Postgraduate Program in Psychology at Universidade Federal de Juiz de Fora, Juiz de Fora-MG, Brazil.

Pollyanna Santos da Silveira is an Assistant Professor in the Department of Psychology at the Catholic University of Petrópolis, Petrópolis-RJ, Brazil, and a Collaborating Professor in the Psychology Graduate Program at the Federal University of Juiz de Fora, Juiz de Fora-MG, Brazil.

\section{Authors' Contribution:}

All authors made substantial contributions to the conception and design of this study, to data analysis and interpretation, and to the manuscript revision and approval of the final version. All authors assume public responsibility for the manuscript content.

\section{Associate Editor:}

Wanderlei Abadio de Oliveira

Received: Apr. 03, 2021

1st Revision: Jun. 17, 2021

Approved: Jul. 24, 2021
How to cite this article:

Maia, M. F. C., Santos, B. F., Castro, L. C., Vieira, N. S. T., \& Silveira, P. S. (2021). Acceptance and commitment therapy and drug use: A systematic review. Paidéia (Ribeirão Preto), 31, e3136. doi:https://doi.org/10.1590/1982-4327e3136 